\title{
A Comparative Evaluation of Macular Thickness after Phacoemulsification and Manual SICS in Diabetic Patients by Optical Coherence Tomography
}

\author{
Saswati Biswas ${ }^{1}$, Santosh Yadawrao Ingle ${ }^{2}$, Samiran Das ${ }^{3}$ \\ ${ }^{1}$ Junior Resident, Susrut Eye Foundation and Research Centre, Kolkata, West Bengal, India. \\ ${ }^{2}$ Consultant Ophthalmologist, Swara I Care Hospital, Amravati, Maharashtra, India. \\ ${ }^{3}$ Senior Clinical Fellow, Department of Anaesthesia and Critical Care, Bedford Hospital NHS Trust, UK
}

Corresponding Author: Santosh Yadawrao Ingle

\begin{abstract}
Background: The main aim of the study is to compare the change in macular thickness after uncomplicated phacoemulsification versus uncomplicated manual SICS in known diabetic patients by optical coherence tomography

Methods: This study was an observational study involving 50 patients with each group having 25 patients. Group 1 was operated with Phacoemulsification through limbal $2.8 \mathrm{~mm}$ incision with Foldable PCIOL implantation. \& Manual small incision cataract surgery through 5.5 to $6.5 \mathrm{~mm}$ incision with sclerocorneal tunnel with PMMA PCIOL implantation. For all patients, macular OCT was performed during preoperative period $\&$ post-op $1^{\text {st }}$ day, $7^{\text {th }}$ day, $1^{\text {st }}$ month, $3^{\text {rd }}$ month \& $6^{\text {th }}$ month. Statistical software SPSS, version 21.0 was used for statistical analysis.
\end{abstract}

Results: In both PHACO \& SICS group MCFT rose steadily during post-operative period and SICS group shows high rise during follow up. The MCFT shows a difference between PHACO \& SICS group with the highest MCFT observed in 1st month follow up i.e., 231.6 micrometer (SD \pm 7.831 ) in PHACO group \& 241.64 (SD $\pm 7.35)$ micrometer in SICS group. The MCFT returned to near pre-op value by the 6th month.

Conclusion: There is no effect of age and sex on macular thickness before and after in both PHACO and SICS groups. In SICS group significant macular thickness was observed as compared to PHACO group, so there should be more cautious to undertake SICS in those patients who are at risk of developing macular edema or who have a higher macular thickness as seen in diabetes patients.

Keywords: Phacoemulsification (PHACO), small incision cataract surgery (SICS), Cystoid macular edema

\section{INTRODUCTION}

Commonly performed ocular surgery is cataract. Many of its long-term effect on retinal layer are still unknown. These retinal effects may be because of inflammation of aging vasculature. There is a need for new investigations to improve this long-term effect ${ }^{1}$. Over the years, as there are newer advancements in cataract surgery which decrease in size of incision for lens extraction. This results in decreased operative time and rapid recovery. Due to this, goal of surgery has changed from Restoration of sight to early Restoration of visual acuity ${ }^{2}$.

Cystoid macular edema (CME) is most common in cataract surgery causes diminution of vision. In the skilled hands, decrease incision size and less time minimize the incidence of CME. Angiographic CME is approximately $19 \%$ in phacoemulsification (PHACO) which is less than 20 to $30 \%$ and 50 to $75 \%$ in ExtraCapsular Cataract Extraction (ECCE) and 
Intra-Capsular Cataract Extraction (ICCE) respectively ${ }^{3}$.

But this angiographic CME does not always decrease the post-operative visual. Iris trauma, Diabetes mellitus, Posterior capsular dehiscence is other risk factor for the development of CME. Increase prostaglandin also induce edema ${ }^{4}$.

Modern cataract surgery with a small and self-sealed corneal incision along with the use of a foldable intraocular lens in the bag reduces CME. Ocular Coherence Tomography is used to detect macular edema is a newer real-time investigation ${ }^{5}$. There is little data available to compare between two groups, small incision cataract surgery (SICS) and Phacoemulsification (PHACO) in a patient with diabetes mellitus.

\section{MATERIALS \& METHODS}

This study was an observational study conducted at Susrut Eye Foundation and Research Centre, Kolkata West Bengal. Institutional ethics committee permission and departmental research committee permission was obtained before the study. All patients who fulfilled the inclusion and exclusion criteria of the study were included.

The study was a prospective randomized study. The study population consisted of males and females $\geq 50$ years of age with diabetic patients. A total of 50 patients with cataract in one eye were subdivided into two groups of 25 each, as follows:

Group 1: Phacoemulsification through limbal $2.8 \mathrm{~mm}$ incision with Foldable PCIOL implantation.

Group 2: Manual small incision cataract surgery through 5.5 to $6.5 \mathrm{~mm}$ incision with sclerocorneal tunnel with PMMA PCIOL implantation.

\section{Inclusion Criteria:}

1. Patient having controlled diabetes of any duration.

2. Patient having cataract up to grade 3 nuclear Sclerosis.

\section{Exclusion Criteria:}

1. Uncontrolled diabetic patients.

2. Grade IV and above nuclear sclerosis

3. Patient on Ocular Medication of long term due to reasons like Glaucoma Uveitis, etc.

4. Patients having any Macular change (clinically) on stereoscopic slit lamp Biomicroscopy.

5. Patient having history of any kind of previous ocular surgery.

6. Complicated Cataract surgery e.g., Vitreous loss, PCR.

7. Other degenerative condition of Macula e.g., ARMD.

8. Decompensated renal disease or uncontrolled hypertension.

9. Macular edema due to other causes e.g., Secondary to venous occlusion.

All patients were evaluated in the preoperative phase with patient history and visual acuity been tested with Snellen's test types. A detailed evaluation of the anterior segment had been done using oblique illumination and slit-lamp examination and fundus examination had been performed under full mydriasis by 90Dand slit lamp biomicroscope. Macular OCT has been done for all patients. Calculation of IOL Power Axial length calculation by A-scan ultrasonography IOL power calculation by SRK II (Sanders, Retzlaff \& Kraff) formula has been performed ${ }^{6}$.

Post-operative evaluation has been done on the $1^{\text {st }}$ day, $7 \mathrm{t}^{\mathrm{h}}$ day, $1^{\text {st }}$ month, 3 month \& 6 months. Corrected VA for distance has been calculated. Optical coherence tomography has been done on the $7^{\text {th }}$ day, $1^{\text {st }}$ month, $3^{\text {rd }}$ month $\& 6^{\text {th }}$ month.

All postoperative patients were prescribed standard treatment regime consisting of Moxifloxacin $(0.3 \%)$ e/d q.i.d for 2 weeks, Tropicamide (0.8\%) + Phenylephrine $(5 \%)$ e/d OD for 1 or 2 weeks, Prednisolone acetate (1\%) e/d starting with 8 times per day then gradually tapered over $1 \frac{1 / 2}{2}$ month period of time. 


\section{STATISTICAL ANALYSIS}

All continuous variables (like age, sex, CFT) were presented as mean \pm SD and compared between groups by using an independent sample t-test for normally distributed data or Mann- whiney U- test for non-normal data as appropriate. All qualitative variables (like sex, operated eye, etc.) were expressed as numbers and compared between groups by using chisquare of Fischer's exact test as appropriate. A p-value $<0.05$ was considered statistically significant. Statistical software SPSS, version 21.0 was used for statistical analysis.

\section{RESULTS}

Among the study population consisting of males and females, the Average age for PHACO group was 63.88 years for 25 patients and minimum age was 55 years while maximum age was 75 years.
The average age for SICS group was 62.76 years for 25 patients and minimum age was 50 years while maximum was 85 yrs. Considering the gender parameter in Phaco group out of 25 patients $13(52 \%)$ were male, whereas $12(48 \%)$ were female. In SICS group out of 25 patients, $9(36 \%)$ were male, whereas 16 (64\%) were female.

\section{Effect of gender on Mean CFT}

Mean Central Foveal Thickness (MCFT) in micron between the two groups (PHACO and SICS) was calculated and tabulated. Data was statistically analyzed using Student's t-test. The outcome in MCFT was compared on $3^{\text {rd }}$ day, $7^{\text {th }}$ day, $1^{\text {st }}$ month, $3^{\text {rd }}$ and $6^{\text {th }}$ month follow up between two sexes undergoing either PHACO or SICS. There was no significant difference between MCFT on pre-operative period in PHACO and SICS group $(p=0.38)$

\begin{tabular}{|l|l|l|l|l|l|l|}
\hline Sex & Pre-op & $\mathbf{1}^{\text {st }}$ Day & $\mathbf{7}^{\text {th }}$ day & $\mathbf{1}^{\text {st }}$ month & $\mathbf{3}^{\text {rd }}$ month & $\mathbf{6}^{\text {th }}$ month \\
\hline Male & 209 & 223 & 232.22 & 245 & 216 & 214.56 \\
\hline Female & 204.06 & 219.3 & 229 & 239.7 & 213.06 & 211 \\
\hline p-value & 0.15 & 0.15 & 0.29 & 0.09 & 0.25 & 0.16 \\
\hline
\end{tabular}

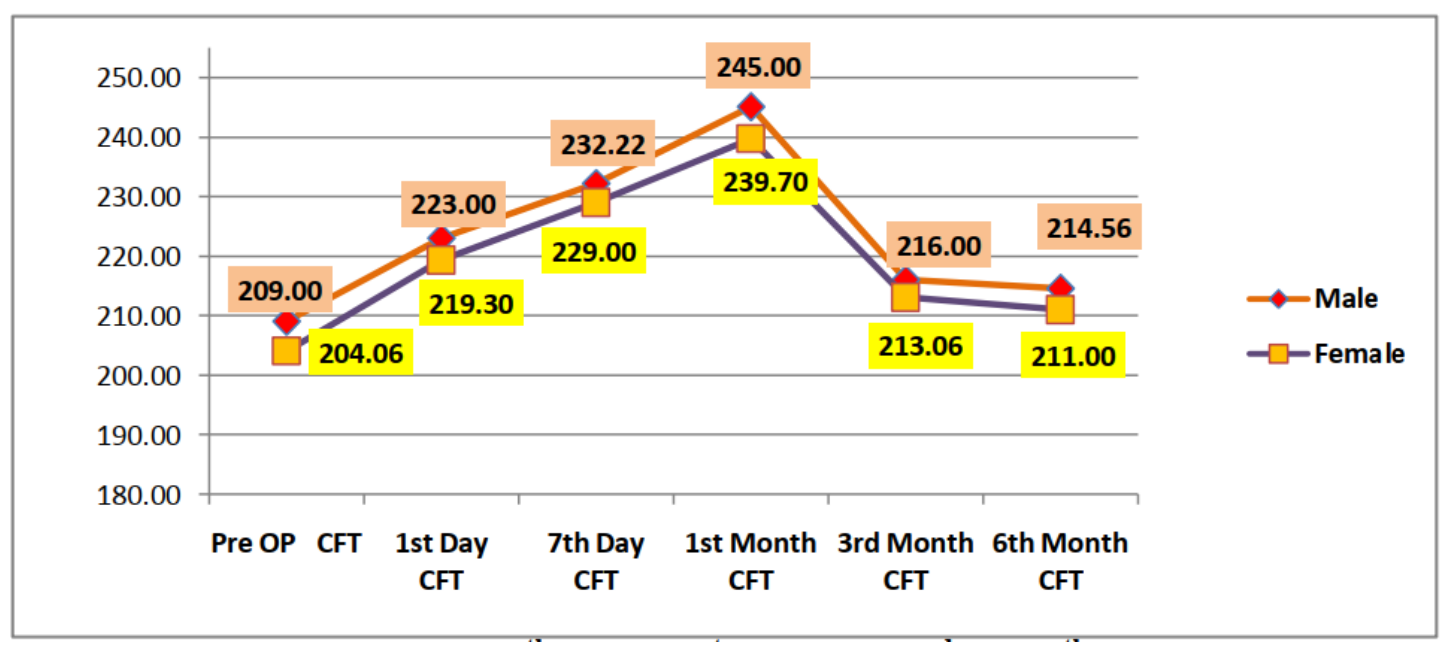

\section{Comparison of MCFT between group $1 \& 2$}

MCFT between two groups was calculated, tabulated and data was statistically analyzed using Students t-test. But MCFT was always higher in SICS group than PHACO group during the whole post-operative period.

\begin{tabular}{|l|l|l|l|l|l|l|}
\hline & Pre op & $\mathbf{1}^{\text {st }}$ Day & $\mathbf{7}^{\text {th }}$ Day & $\mathbf{1}^{\text {st }}$ Month & $\mathbf{3}^{\text {rd }}$ Month & $\mathbf{6}^{\text {th }}$ Month \\
\hline PHACO group & 203.88 & 213.76 & 221.64 & 231.6 & 207.76 & 206.58 \\
\hline SICS group & 205.84 & 220.64 & 230.16 & 241.64 & 214.12 & 212.33 \\
\hline p-value & 0.38 & 0.001 & $<0.0001$ & $<0.0001$ & 0.001 & 0.006 \\
\hline
\end{tabular}


Saswati Biswas et.al. A comparative evaluation of macular thickness after phacoemulsification and manual SICS in diabetic patients by optical coherence tomography.

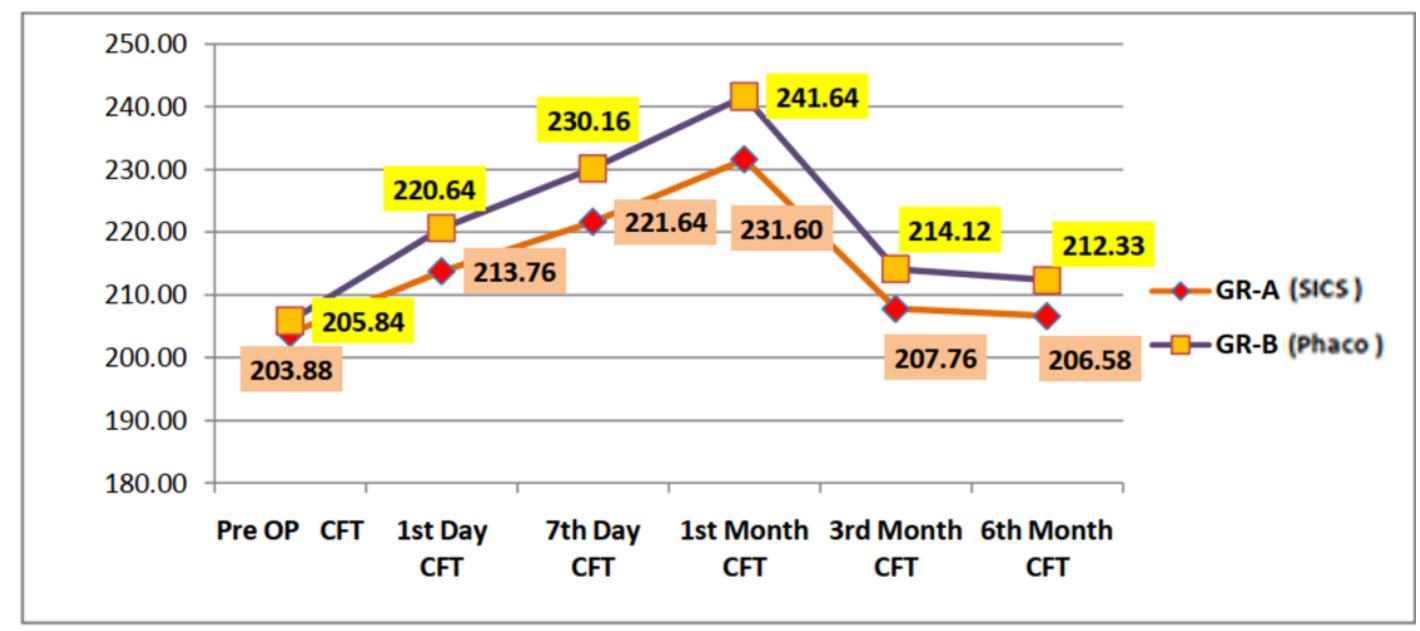

Mean central foveal thickness between the two groups was calculated and statistically analyzed using student's t-test. MCFT gradually increased from pre-op value till $1^{\text {st }}$ month post-op. in both groups. By the end of $6^{\text {th }}$ month post-op, the MCFT reverted to near pre-operative value. The highest MCFT in both groups was at $1^{\text {st }}$ month PHACO (241.6, SD 7.39) and SICS (231.6, SD 7.83). There was no significant difference between MCFT on preoperative day in both groups $(\mathrm{p}=0.38)$. However, MCFT was always higher in SICS group during the complete 6 month period.

\section{DISCUSSION}

Cystoid macular oedema is common cause of unexpected poor vision after cataract surgery ${ }^{7}$. In India and Nepal SICS have been used in many centers with comparable visual outcomes, significantly faster, less expensive and requires less technology ${ }^{8}$. Fundus fluorescein angiography has been the gold standard for diagnosing $\mathrm{CME}^{9}$. With the advent of OCT, which give result in an office setting and is non- invasive, more sensitive than FFA or clinical examination is detecting even mild CME. OCT is superior in describing axial distribution of fluid and it achieves good reproducibility ${ }^{10}$. MCFT rise in both groups during the postoperative period. A higher rise in MCFT was noted in SICS group throughout the follow up. Significance difference in MCFT between PHACO and SICS group was noted on $3^{\text {rd }}$ and $6^{\text {th }}$ month follow up (p-value was 0.001 and 0.006 respectively).

The highest MCFT was noted in 1st month follow up in both groups, 231.6 micro $\mathrm{mm}$ (SD-7.83) in PHACO group, 241.6 micro mm (SD- 7.39) in SICS group. They came near to the pre-operative value in both groups, 206.58 micro mm (SD- 7.6) in PHACO group and 212 micro mm (SD 6.0) in SICS group, but the values were still significantly higher than preoperative values in SICS group than PHACO group. Clinically significant macular edema was not found at any point in time in any patient during this study. MCFT value never went above 300 micro $\mathrm{mm}$ in any patient in any follow up. We did not find any specific effect of diabetes mellitus on the result, but the higher pre-operative MCFT than the other studies that were done in normal healthy patients, suggests the effect of diabetes on macular thickness in both the groups although clinically not significance

\section{CONCLUSION}

In this study total of 50 cataract patients were enrolled, who were also having a history of diabetes mellitus are randomized into two groups, one group undergoing Phacoemulsification and other Manual SICS. Macular OCT was done in all patients on pre-operative day, $1^{\text {st }}$ day, $7^{\text {th }}$ day, $1^{\text {st }}$ month, $3^{\text {rd }}$ and $6^{\text {th }}$ months follow up. Based on the study it can be concluded that age and sex have no effect on macular thickness before and after in PHACO and 
SICS group. Significance macular thickness was observed in SICS group as compared to PHACO group, so there should be more caution to undertake SICS in those patients who are at risk of developing macular edema or who have a higher macular thickness as seen in diabetes patients.

Acknowledgement: None

\section{Conflict of Interest: None}

\section{Source of Funding: None}

\section{Ethical Approval: Approved}

\section{REFERENCES}

1. Lobo CL, Faria PM, Soares MA, Bernardes RC, Cunha-Vaz JG. Macular alterations after small-incision cataract surgery. J Cataract Refract Surg. 2004;30(4):752-60.

2. Wright PL, Wilkinson CP, Balyeat HD, Popham J, Reinke M. Angiographic cystoid macular edema after posterior chamber lens implantation. Arch Ophthalmol. 1988;106: $740-4$.

3. Hitchings RA, Chisholm IH. Incidence of aphakic macular oedema: A prospective study. Br J Ophthalmol. 1975;59:444-50.

4. Henderson BA, Kim JY, Ament CS, Ferrufino-Ponce ZK, Grabowska A, Cremers SL. Clinical pseudophakic cystoid macular edema. Risk factors for development and duration after treatment. $\mathbf{J}$ Cataract Refract Surg. 2007;33(9):1550-8.

5. Mandal P, Srivastava SR. Comparative evaluation of macular thickness after phacoemulsification vs. Manual sics by ocular coherence tomography in diabetic patients. J Evid Based Med Healthc. 2016;3(99):5477-81.

6. Dang MS, Sunder Raj PP. SRK II formula in the calculation of intraocular lens power. Br J Ophthalmol. 1989;73:832-826.

7. Albert DM; Miller JW; Azar DT. Albert \& Jakobiec's principles and practice of phthalmology. 3rd ed. Saunders Elsevier; 2008. 1551-1553 p.

8. Ruit S, Tabin G, Chang D, Bajracharya L, Kline DC, Richheimer W, et al. A Prospective Randomized Clinical Trial of Phacoemulsification vs Manual Sutureless Small-Incision Extracapsular Cataract Surgery in Nepal. Am J Ophthalmol. 2007;143(1):32-8.

9. Tabin G, Chen M, Espandar L. Cataract surgery for the developing world. Vol. 19, Current Opinion in Ophthalmology. 2008. 19(1). 55-9.

10. Cunha-Vaz JG. The blood-retinal barriers. Doc Ophthalmol. 1976;41(2):287-327.

How to cite this article: Biswas S, Ingle SY, Das S. A comparative evaluation of macular thickness after phacoemulsification and manual SICS in diabetic patients by optical coherence tomography. International Journal of Research and Review. 2021; 8(7): 468-472. DOI: https://doi.org/10.52403/ijrr.20210766 